DOI 10.37882/2223-2982.2020.05-2.05

\title{
ЯВЛЕНИЕ ГИБРИДИЗАЦИИ ВТОРОГО И ТРЕТЬЕГО ПОРЯДКА В АНГЛИЙСКОЙ ТЕРМИНОЛОГИИ КОМПЬЮТЕРНЫХ СТАНДАРТОВ И МИКРОЭЛЕКТРОНИКИ
}

\section{SECOND AND THIRD ORDER HYBRIDIZATION PHENOMENON IN ENGLISH TERMINOLOGY OF COMPUTER STANDARDS AND MICROELECTRONICS \\ E. Kerber \\ I. Belikova \\ Yu. Kosterina}

Summary: Language is tended to economy of linguistic means and that leads to a large number of shortenings. This phenomenon is not bypassed by terminology, where abbreviations and hybrid formations are the overwhelming number of abbreviations. To a lesser extent there are clipping, fusion and straining. The paper attempts to trace the evolution of abbreviations from terminology combination to second and third-order hybrid on English language material. Shortenings in computer standards and microelectronics served as the subject of the study.

Structural models of hybrid formations in terms of synchronia and diachronia are considered, as well as the peculiarities of their use. Their productivity is noted.

Keywords: terminological word combination, abbreviation, hybrid formation, computer standard.
Кербер Елена Владимировна

К.филол.н., дочент, ФГБОУ ВО «Омский государственный технический университет»

Ikerber@mail.ru

Беликова Ирина Александровна

К.фрилол.н., дочент, ФГБОУ ВО «Омский государственный технический университет» irina.belikova@gmail.com

Костерина Юлия Евгеньевна

К.фрилол.н., доцент, ФГБОУ ВО «Омский государственный технический университет» kosterina77@mail.ru

Аннотация: Стремление языка к экономии языковых средств способствует появлению большого числа сокращений. Данное явление не обходит стороной и терминологию, где подавляющим числом сокращений являются аббревиатуры и гибридные образования. В меньшей степени - усечения, слияние, стяжение. В статье сделана попытка проследить эволюцию сокращений от терминологического сочетания до гибрида второго и третьего порядка на материале английского языка. В качестве объекта исследования послужили сокращения в области компьютерных стандартов и микроэлектроники.

Рассматриваются структурные модели гибридных образований в плане синхронии и диахронии, отмечается их продуктивность, а также особенности их употребления.

Ключевые слова: терминологическое сочетание, аббревиатура, гибридное образование, компьютерный стандарт.

вслед за советским филологом Д.И. Алексеевым под аббревиацией будем понимать «способ создания номинаций для тех понятий и реалий, которые были первоначально обозначены описательно, с помощью атрибутивных словосочетаний» [цит. по Сергеева, 2013, 175]. И аббревиатура является результатом данного процесса.

В класс буквенных аббревиатур, объединяющий акронимы и алфавитизмы входят графические и лексические аббревиатуры [Там же, с. 176].

Лексическую аббревиацию следует рассматривать как способ словообразования, в результате которого возникают различные аббревиатурные лексемы. Другими словами, аббревиатура представляет собой языковой знак, единицу, характеризующуюся признаками слова. К таковым относятся цельнооформленность, фонетическая и грамматическая целостность. Под графическими аббревиатурами понимают такие аббревиатурные номинации, которые используются исключительно в 
письменной речи и не имеют соответствующей звуковой формы выражения в устной речи. Д. И. Алексеев, в свою очередь, отмечает, что графические аббревиатуры существуют только для зрительного восприятия и при чтении должны расшифровываться [цит. по Сергеева, $2013,176]$. Не стоит путать графическую аббревиатуру с графическим вариантом термина, который подразумевает различие в характере написания, но сохраняет тождественность в лексическом значении [2, с. 130]. Так графическим вариантом термина MicroSATA является (uSATA или $\mu$ SATA). Графический элемент $\boldsymbol{\mu}$ - греческая буква «мю», обозначающая приставку -микро, согласно Международной системе единиц (СИ), а буква и - ее латинский аналог.

Пополнение фонда терминов-аббревиатур, происходит за счет сокращения устойчивых терминологических сочетаний (ТС) ввиду частотности их употребления и для экономии языковых средств. И. Г. Кудрявцева, анализируя формальные структуры терминологических сочетаний выделила некоторые особенности структурных моделей английских терминологических словосочетаний. Одной из таких особенностей ученый называет наличие в структуре словосочетаний аббревиатур, дающих возможность передавать максимум информации при минимуме формы: remote LAN access, ICA1P network, ISDN media access control. Компонент-аббревиатура в английских терминах-словосочетаниях может занимать положение стержневого компонента или выступать в функции определяющего компонента словосочетания: Internet Server API, ICMP network [3, с. 13]. В то же время, как отмечают исследователи, «аббревиатуры создаются сокращением материальных единиц производящего комплекса и конденсацией, уплотнением, но не сокращением его семантики» [цит. по Вишнякова, 2014, 62].

М.А. Ярмашевич обращает внимание на «ускоренную динамику» аббревиатурных единиц и «высокую генеративную способность» моделей аббревиатурного словообразования $[5$, с.8,10]. Этот факт, на наш взгляд, является основополагающим в том, что частью гибридных образований становятся именно аббревиатуры.

Далее перейдем к рассмотрению гибридных новообразований.

В переводе с греческого «гибрид» - это «помесь», т.е. объект, сочетающий в себе свойства других (двух или более) объектов. Подобные сочетания (словосочетания) в специальной литературе получили названия: гибридотермины (В.П. Скуиня), гибридные образования (словосочетание) гибридные композиты (словосложение), ДГО - дефисные гибридные образования (Е.П. Снегова), слова-«кентавры» (Л.П. Крысин), визуальные неологизмы, слова-вкладыши (Е.В. Маринова), иноязычные вкрапления (А.А. Леонтьев), «заимствования-смеси» (Э.
Хауген). В то время как сами элементы словосочетания могут называться «эндогенными» и «экзогенными» (М.Н. Озолина), калькированными, заимствованными (В.Л. Попова), «автохтонными и иноязычными» (Л.А. Нефедова).

Таким образом, в лингвистической науке под гибридным образованием понимается смешение словообразовательных элементов (иноязычных/ исконных) и форм (сокращенных/полых).

Опираясь на материал исследования, гибридные образования будут нами рассмотрены исключительно с точки зрения сочетания в одной лексической единице кратких и полных элементов. Данная категория гибридных терминов характеризуется сокращением материальной оболочки словосочетания с сохранением его семантической целостности в соответствии с «законом экономии речевых средств».

Ряд ученых, такие как Л.Б. Ткачева, Л.Г. Просвирнина, Е.Д. Полетаева, О.С. Каравайская, И.А. Беликова занимались исследованием терминологических сокращений, в том числе и гибридных образований и дали собственные определения этому понятию. Таким образом, под гибридным образованием ученые понимают «сокращенные термины, в состав которых входят полнозначные несокращенные компоненты терминологического сочетания» [цит. по Просвирнина, 2010, 11]; «сочетание, в котором неизменной сохраняется часть элементов терминосочетания при сокращении некоторых его компонентов» [7, с.56-57]; «частично сокращенные слова или словосочетания, которые образуются в результате сложения усеченного элемента и полнозначного слова или словосочетания» [8, с.927]; «комбинацию из несокращенного и сокращенного термина» [9, с.1007].

Ряд терминологических исследований подтверждает, что гибридизация как способ сокращения терминов занимает второе место после инициального сокращения: работы в области интеллектуальной собственности и экономики (Л.Г. Просвирнина), нефтепровода (Н.В. Горохова), компьютерной техники (И.А. Беликова), химии (А.А. Елизарова, А.А. Васильева), искусственного интеллекта (Т.Н. Винокурова), транспортной логистики (Е.Д. Полетаева) и др. Синтаксический способ слово - и терминообразования весьма продуктивен в области программного и аппаратного обеспечения, что подтверждается большим количество терминов - многокомпонентных ТС, аббревиатур и гибридных образований

Согласно С. В. Гриневу, образование словосочетаний следующего уровня на базе исходных выглядит таким образом: «путем их сочетания, либо путем добавления определяющих компонентов к исходному сочетанию» [10, с.142]. Эта закономерность прослеживается и в процессе образования гибридных образований: со- 
кращения устойчивых ТС ввиду частотности их употребления и для экономии языковых средств приводит к образованию аббревиатур (USB: Universal Serial Bus), далее компонент-аббревиатура либо становится частью отаббревиатурного неологизма-композита (micro-USB, non-USB-aware) либо гибридного образования, занимая положение стержневого компонента или выступая в функции определяющего компонента словосочетания (USB connector). Впоследствии отаббревиатурный композит также становится компонентом ТC (USB-aware operating system).

\section{Материал и методы исследования}

Рассматривая гибридные образования, как терминологическое сочетание, частью которых является аббревиатура, мы в в своем исследовании будем опираться на определение И.А. Беликовой, в котором гибридные образования характеризуются как «многокомпонентные терминологические сочетания, где в качестве одного или нескольких компонентов выступают инициальные сокращения [11, с.100].

В данной статье нами предпринята попытка проследить дальнейший процесс гибридизации многокомпонентных ТС на примере терминов из области компьютерных стандартов и микроэлектроники. Исследование проводилось на основе структурного анализа, позволяющего определить основные модели гибридных образований в исследуемой области с учетом количества компонентов, составляющих терминологическую единицу, а также установить характер их внутренних связей.

Проведенное исследование позволяет доказать, что процесс гибридизации терминов в компьютерной терминологии развивается столь стремительно, что приводит к созданию гибридов второго порядка инициализма, образованного от начальных букв гибридного терминологического сочетания, имеющего в своем составе одну или несколько аббревиатур.

В рамках лингвистического подхода был использован метод сравнительно-сопоставительного анализа, структурные методы морфемного и словообразовательного анализа, а также контекстный анализ

\section{Результаты исследования}

Процессы, которые приводят к появлению терминологических сочетаний во многом схожи с процессами, которые приводят к появлению гибридных образований (ГО), принимая во внимание синтаксический способ их образования. Гибридные новообразования проходят эволюционный путь, начиная от терминологического сочетания, которое в силу частотности употребления с течением времени сокращается до начальных букв. Да- лее инициальное сокращение становится лексическое единицей языка и образует новое терминологическое сочетание с той или иной лексемой, устанавливая атрибутивный вид связи с ядерным компонентом сочетания. Данное терминологическое сочетание мы называем гибридным образованием. Следующий шаг - это появление сокращенной формы гибридного терминологического сочетания, которая с новой лексемой образует гибрид второго порядка и т.д.

В процессе номинации сокращения важно учитывать диахронический аспект, т.е. временной интервал образования термина: в какой момент аббревиатура стала гибридом второго порядка. С точки зрения структуры - это аббревиатура, с позиции диахронического подхода - гибрид второго порядка.

Рассмотрим структурные связи между компонентами в гибридных неологизмах и модели, по которым они строятся.

1. Компоненты гибридного образования (ГО), которые впоследствии не образуют новое инициальное сокращение (ГО2).

1) $\mathrm{abbr}+\mathrm{N}$

ATAPI controller, USB device, USB host, ASPI structure

2. Компоненты гибридного образования (ГО), которые впоследствии образуют новое сочетание (ГО2) или результатом которого становится новая лексическая единица (композит или инициальное сокращение). Данная модель чаще образует второй (на временном отрезке) порядок сокращения. 1) $\mathrm{adj}+\mathrm{abbr}$ или Ved + abbr virtual SAN > VSAN, Parallel ATA > PATA, Serial ATA > SATA, External SATA > eSATA, Enhanced IDE $>$ EIDE.

2) abbr + TC

SCSI Trade Association > SCSITA; SCSI Pass

Through Interface > SPTI; USB Implementers

Forum > USB-IF; SCSI Pass Through Direct > SPTD.

3) $a b b r+a b b r$

USB MSC > UMS < Universal Serial Bus Mass

Storage Class

USB-HID > Universal Serial Bus Human Interface

Device

JSON-RPC > JavaScript Object Notation Remote

Procedure Call

3. По такой же схеме (синтаксический способ образования) строятся гибридные сочетания, в которых одним из компонентов является гибрид второго порядка. Пожалуй, это одни из самых сложных, но в тоже время, интересных вариантов, встречающихся на сегодняшний день.

1) $\Gamma \mathrm{O} 2+\mathrm{N}$

ASPI structure < Advanced SCSI Programming Interface structure < Advanced Small Computer 
System Interface Programming Interface structure UASP standard < USB Attached SCSI Protocol standard < Universal Serial Bus Attached Small Computer System Interface Protocol standard

EUHP adapter < eSATA USB Hybrid Port adapter < External Serial Advanced Technology Attachment Universal Serial Bus Hybrid Port adapter

PMTU Discovery > PMTUD < Path MTU Discovery $<$ Path Maximum Transmission Unit Discovery

2) $\mathrm{N}+\mathrm{rO} 2$

Power eSATA > eSATAp < Power External Serial Advanced Technology Attachment

3) $\Gamma \mathrm{O} 2+\mathrm{TC}$

ASPI manager software < Advanced SCSI Programming Interface manager software < Advanced Small Computer System Interface Programming Interface manager software

NPIV Functionality protocol < N_Port ID Virtualization Functionality protocol < Node Port Identifier Virtualization Functionality protocol

4. И, наконец, нами был выявлен гибрид третьего порядка (ГОЗ).

Две аббревиатуры VHSIC < Very High Speed Integrated Circuit и $\mathrm{HDL}<$ Hardware Description Language образуют сложный термин с дефисным написанием VHSIC-HDL, который, в свою очередь сокращается до аббревиатуры VHDL, оставляя только значимые компоненты и становясь гибридом второго порядка (ГО2). Далее гибрид второго порядка участвует в образовании следующего более сложного новообразования VHDL Procedural Interface и затем сокращается до VHPI. Description Language (DL) как менее значимый элемент аббревиатуры опускается, уступая место начальным буквам нового терминологического сочетания, которые вместе с усеченной аббревиатурой образуют гибрид третьего порядка.

Еще один пример. VITAL < VHDL Initiative Towards ASIC Libraries. Данное терминологическое сочетание уже содержит гибрид второго порядка VHDL (сокращение от VHSIC-HDL) и аббревиатуру ASIC. Дальнейшее их сокращение приводит к гибриду третьего порядка VITAL.

В заключении обзора гибридных образований хотелось бы обратить внимание на особенность употребления вышеупомянутых аббревиатур в контексте предложения, которая заключается в повторе последнего компонента, содержащегося в инициализме:

1. The EUHP port is compatibility with existing eSATA cable and USB cable. (где $\mathrm{P}$ - port).

2. ... to support HID devices such as keyboards, mice, game controllers. (где D - device).

3. Typical examples for MSC class devices are (где C class).
4. The probe-scsi-all command will show both internal and external devices on every SCSI interface (где I interface). На наш взгляд, этот прием используется, во-первых из контекстуальных соображений, уточняя какая именно лексическая единица приводится в сокращении, а, во-вторых упрощает ее встраиваемость в структуру предложения как элемента письменной речи, тем самым облегчая ее восприятие.

Далее приведем ряд примеров, заслуживающих особого внимания.

Рассмотрим термин PHY, а также синтаксические связи между компонентами гибридных образований, частью которых он является. Этот термин представляет собой усечение от Physical layer - физический уровень - и обозначает интегральную схему, предназначенную для выполнения функций физического уровня сетевой модели OSI. PHY входит в составе гибридного образования Ethernet PHY - Компонент, работающий на физическом уровне сетевой модели OSI. Термин M-PHY обозначает физический уровень интерфейса процессора для мобильных ПК. M-PHY < MIPI Physical layer < Mobile Industry Processor Interface Physical Layer. Термин образован от первой буквы инициализма и усечения словосочетания, образуя композит второго порядка. Постпозицию в гибридном образовании М-РНY трактуют как суффикс, указывающий на конкретный протокол физического уровня («PHY may also be used as a suffix to form a short name referencing a specific physical layer protocol»). Гибридное образование второго порядка PHYceiver $<$ Ethernet physical transceiver < Ethernet physical layer transceiver (transmitter+receiver) - чип, который реализует функции аппаратной отправки и приема Ethernet кадра - представляет собой стяжение терминосочетания physical layer tranceiver, где tranceiver, в свою очередь, уже является усечение терминов (transmitter+ receiver). У данного термина существует синоним PHY chip.

Среди гибридных образований второго порядка отдельно можно выделить графические гибридные образования представляющие собой графические частично мотивированные варианты. Так в терминах xSATA < eXternal SATA и xHCl < eXtensible Host Controller Interface буква $x$ была выбрана для сокращения первого компонента на основе фонетической схожести с первым слогом, создав определенную трудность в интерпретации гибрида, так как в обоих случаях употребляются разные слова. Следующий термин 10BASE-T означает физический стандарт Ethernet, позволяющий компьютерам связываться при помощи кабеля типа «витая пара». В названии стандарта 10 указывает на скорость передачи данных в 10 Мбит/с. Слово BASE написано заглавными буквами, не являясь при этом 
инициальным сокращением, а усечением от термина baseband signaling - передача сигналов без модуляции. Буква Т происходит от словосочетания «twisted pair» (витая пара), обозначая используемый тип кабеля. В разряде графических вариантов терминов можно привести термин USB-UART < Universal Asynchronous Receiver-Transmitter-Universal Serial Bus, который означает переходник для доступа к UART через USB. Его не следует рассматривать как композит или сложный термин с дефисным написанием. В сложном термине отношение между значениями двух элементов представляет собой подчинительную семантическую связь, где основная семантическая нагрузка приходится на второй (последний) элемент слова [12, с. 51], и где один компонент дополняет, уточняет другой. Дефис в термине USB-UART несет смысловую нагрузку «через», «к», «связь», «стыковка» и является графическим аналогом выражения «от одного к другому». Компоненты подобного гибридного образования самостоятельны и отношение между значениями двух элементов представляет собой сочинительную связь. Тоже самое верно в отношении термина USB-HID, который означает класс устройств USB для взаимодействия с человеком, или устройство «иsb-человек» (cp. JSON-RPC протокол удаленного вызова процедур, использующий JSON для кодирования сообщений, где прослеживается подчинительная связь).

Особый интерес представляет термин RESTful (RESTful). REST < Representational State Transfer означает архитектурный стиль взаимодействия компонентов распределенного приложения в сети. Данный термин образован не совсем типичным способом. Широко распространенными компонентами сложных терминов, со значением «основанный на», «совместимый с» и «дружественный», использующиеся в терминологии компьютерной техники на сегодняшний день являются: -based, -compliant, -friendly. Однако, в термине RESTful используют суффикс прилагательного -ful, выделяя тем самым термин из ряда однотипных, так как деривационные элементы у аббревиатур - явление не частое. Деривационный элемент в данном термине скорее признак окказиональности, нежели пример характерного для аббревиатуры морфологического способа образования производных терминов. Cambridge Dictionary определяет значение суффикса -ful как «full of, characterized by, having the qualities of» [13]. The Merriam-Webster online dictionary дает следующую дефиницию суффиксу: «having the stated quality to a high degree» [14]. Таким образом, суффикс выбран не только из соображений благозвучия, экономии языковых средств, но, вероятно, и с целью подчеркнуть значение — «в полном соотвествии с ...». Также особую коннота- цию некоторой исключительности передает графический вариант термина, где -ful пишется курсивом. Таким образом, термин RESTful приобретает следующее значение - « ...для веб-служб, построенных с учётом REST-архитектуры (то есть не нарушающих накладываемых им ограничений). Термин становится весьма продуктивным и участвует в образовании терминологических гибридных образований RESTful systems, RESTful API, RESTful Web services и др.

\section{ВывоА}

Явление гибридизации второго и третьего порядка на сегодняшний день прослеживается в большей степени на страницах зарубежных изданий и характерно для англоязычного профессионального дискурса. При определении статуса многокомпонентного новообразования (инициальное сокращение или сложный гибрид) важно учитывать временной отрезок, в процессе которого происходило аккумулирование терминов.

Продуктивными моделями у гибридного образования считается сочетание прилагательного с аббревиатурой. Продуктивной моделью у новообразований более высокого порядка можно назвать сочетание гибридного инициализма с существительным.

Гибридное образование второго порядка может иметь статус полноценной единицы общения, удовлетворяющей всем требованиям коммуникации, на что указывает ее реализация как в устной, так и в письменной речи и ее самостоятельное значение.

Совсем недавно ученые говорили о пределе лексической протяженности термина. Таким пределом С. В. Гринев-Гриневич называл семикомпонентные термины-сочетания, объясняя это тем, что «количество информации, воспринимаемой человеком одновременно, определяется объемом непосредственной памяти, а ее пределом является семь элементов» [15, с.142-143]. На сегодняшний день мы близки к тому, чтобы начать считать количество аббревиатурных компонентов в терминоединице и определять функциональный предел гибридного термина.

Специалисты в области IT, а вслед за ними и простые пользователи свободно оперируют звуковой оболочкой сокращенных вариантов и умело жонглируют громоздкими понятиями, демонстрируя ментальные способности в рамках профессионального дискурса и оставляя лексикографам кропотливый труд фиксации подобных языковых конгломератов в словарных статьях. 


\section{ЛИТЕРАТУРА}

1. Сергеева T.С. Аббревиатура в системе лексических сокращений URL: https://www.gramota.net/articles/issn_1997-2911_2013_6-2_47.pdf

2. Маринова Е. В. Визуальные неологизмы: новая графика «старых» слов // Вестник Нижегородского университета им. Н.И. Лобачевского. Серия Филология. Выпуск 1(6). Н. Новгород: Изд-во ННГУ, 2005,- С. 127-132.

3. Кудрявцева И.Г. Особенности формальной структуры и семантические характеристики терминологических словосочетаний (на материале английской и русской специальной лексики научно-технической области «Интернет»): автореф. дис....канд. филол. наук, спец.: 10.02.20.M., 2010. -21 с.

4. Вишнякова Е.А. Место аббревиации в словообразовательной системе современного английского языка // Научные ведомости БелГУ. Серия: Гуманитарные науки. 2014. №6 (177). URL: https://cyberleninka.ru/article/n/mesto-abbreviatsii-v-slovoobrazovatelnoy-sisteme-sovremennogo-angliyskogo-yazyka (дата обращения: 03.04 .2020$)$.

5. Ярмашевич М.А. аббревиация в современных европейских языках: структурный, семантический и функциональный аспекты : автореферат дис. ... доктора филологических наук, - Саратов, 2004. - 40 c.

6. Просвирнина Л.Г. Влияние социально-экономических факторов на формирование гибридного типа сокращения английских экономических терминов / социально-экономические системы: современное видение и подходы: материалы пятой международной научно-практической конференции - омск: сибит, 2010. - с. 145-149.

7. Ткачева Л.Б. Основные закономерности английской терминологии. Томск: Изд-во Том. ун-та, 1987. 200 с.

8. Полетаева Е.Д. Инициализмы как продуктивный тип сокращения в англо-русском научно-учебном тексте экономического дискурса / Е.Д. Полетаева. Текст: непосредственный, электронный // Молодой ученый. — 2016. — № 2 (106). — C. 926-929. — URL: https://moluch.ru/archive/106/25070/ (дата обращения: 16.04.2020).

9. Каравайская 0.С. Сокращения в английской терминосистеме транспортной логистики / 0.С. Каравайская. — Текст: непосредственный, электронный // Молодой ученый. — 2016. — № 28 (132). — C. 1006-1008. — URL: https://moluch.ru/archive/132/36686/ (дата обращения: 16.04.2020).

10. Гринев С.В. Введение в терминоведение. - М., Московский Лицей, 1993.-309с.

11. Беликова И.А. Особенности образования терминов-неологизмов в подъязыке компьютерной техники: дис. ... канд. филол. наук / И.А. Беликова. 0мск, 2004. -147 c.

12. Худинша Е.А. Структурные особенности терминов в английском языке // Концепт. 2014. №S1. URL: https://cyberleninka.ru/article/n/strukturnyeosobennosti-terminov-v-angliyskom-yazyke (дата обращения: 17.04.2020).

13. Cambridge Dictionary https://dictionary.cambridge.org/ru/словарь/ful

14. The Merriam-Webster online dictionary URL: https://www.merriam-webster.com/dictionary/-ful (дата обращения: 17.04.2020).

15. Гринев-Гриневич С.В. Терминоведение / учебное пособие для студ. высш. учеб.заведений. -М.: Издательский центр «Акадаемия», 2008. -304с.

( Кербер Елена Владимировна (Ikerber@mail.ru), Беликова Ирина Александровна (irina.belikova@gmail.com), Костерина Юлия Евгеньевна (kosterina77@mail.ru).

Журнал «Современная наука: актуальные проблемы теории и практики» 